\title{
Redundant and nonredundant organismal functions of EPS15 and EPS15L1
}

\author{
Cinzia Milesi $i^{1}$, Paola Alberici ${ }^{1}$, Benedetta Pozzi ${ }^{1}$, Amanda Oldani ${ }^{1,2}$, Galina V Beznoussenko ${ }^{1} \mathbb{D}$, Andrea Raimondi ${ }^{3}$, \\ Blanche Ekalle Soppo ${ }^{1,4}$, Stefania Amodio ${ }^{1,4}$, Giusi Caldieri, ${ }^{1,4,5}$, Maria Grazia Malabarba ${ }^{1,4,5}$, Giovanni Bertalot ${ }^{4}$, \\ Stefano Confalonieri, ${ }^{1,4}$, Dario Parazzoli ${ }^{1,2}$, Alexander A Mironov' ${ }^{1}$, Carlo Tacchetti ${ }^{3,6}$ @D, Pier Paolo Di Fiore ${ }^{1,4,5}$, \\ Sara Sigismund $d^{1,4,5}$, Nina Offenhäuser ${ }^{1,2}$
}

\begin{abstract}
EPS15 and its homologous EPS15L1 are endocytic accessory proteins. Studies in mammalian cell lines suggested that EPS15 and EPS15L1 regulate endocytosis in a redundant manner. However, at the organismal level, it is not known to which extent the functions of the two proteins overlap. Here, by exploiting various constitutive and conditional null mice, we report redundant and nonredundant functions of the two proteins. EPS15L1 displays a unique nonredundant role in the nervous system, whereas both proteins are fundamental during embryo development as shown by the embryonic lethality of -Eps15/Eps15L1-double KO mice. At the cellular level, the major process redundantly regulated by EPS15 and EPS15L1 is the endocytosis of the transferrin receptor, a pathway that sustains the development of red blood cells and controls iron homeostasis. Consequently, hematopoietic-specific conditional Eps15/Eps15L1double KO mice display traits of microcytic hypochromic anemia, due to a cell-autonomous defect in iron internalization.
\end{abstract}

DOI 10.26508/Isa.201800273 | Received 10 December 2018 | Revised 15 January 2019 | Accepted 16 January 2019 | Published online 28 January 2019

\section{Introduction}

Endocytosis is a process through which cells internalize metabolites, plasma membrane-resident proteins, and signaling receptors, thereby influencing cellular homeostasis. The process is achieved by a variety of entry portals and routes, among which clathrin-mediated endocytosis (CME) is the best characterized one (McMahon \& Boucrot, 2011; Sigismund et al, 2012; Kirchhausen et al, 2014; Robinson, 2015). In addition, endocytosis can occur through clathrin-independent routes (non-clathrin endocytosis), whose molecular determinants and cargo specificity are being elucidated (Lundmark et al, 2008; Sigismund et al, 2012, 2013; Boucrot et al, 2015; Renard et al, 2015; Elkin et al, 2016; Caldieri et al,
2017). Besides clathrin, the main actors of CME are the endocytic adaptors, whose main function is to bridge the membrane cargo with the coat. Endocytic adaptor proteins include the clathrin adaptor protein 2 complex (AP2) and a plethora of accessory adaptor proteins, among which are EPS15 (EGFR pathway substrate 15) and EPS15L1 (EGFR pathway substrate 15 like-1), which control cargo selection and maturation of the vesicles (Mettlen et al, 2009; Traub, 2009; Kirchhausen et al, 2014; Merrifield \& Kaksonen, 2014).

EPS15 and EPS15L1 share 41\% identity and 61\% similarity. They were originally discovered as substrates of the epidermal growth factor receptor (EGFR) (Fazioli et al, 1993; Schumacher et al, 1995; Coda et al, 1998; Salcini et al, 1999) and display features of multidomain scaffolding proteins, containing from $\mathrm{N}$ terminus to $\mathrm{C}$ terminus: (i) three copies of the EH protein-binding module (Wong et al, 1995; Di Fiore et al, 1997; Confalonieri \& Di Fiore, 2002), which can interact with various endocytic proteins (Salcini et al, 1997; Polo et al, 2003); (ii) AP2-binding sites (Benmerah et al, 1996; lannolo et al, 1997); and (iii) ubiquitin-binding domains, UIMs (Polo et al, 2002). In line with their homology, in vitro studies indicated that EPS15 and EPS15L1 are redundant components of the endocytic machinery: they share the same binding partners (van Bergen En Henegouwen, 2009) and endocytosis is redundantly affected when both proteins are functionally impaired. In particular, RNA interference of EPS15 and EPS15L1 in HeLa cells showed that these proteins are redundantly required for the CME of the transferrin receptor (TfR), a prototype of constitutive endocytosis, and of the EGFR, a prototype of ligand-induced endocytosis (Huang et al, 2004). Moreover, EPS15 and EPS15L1 were found to redundantly regulate also the non-clathrin endocytosis of EGFR, together with the endocytic adaptor epsin-1 (Sigismund et al, 2005).

Finally, upon activation of the EGFR, both proteins can be posttranslationally modified, including tyrosine phosphorylation (Fazioli et al, 1993; Coda et al, 1998) and mono-ubiquitination (van Delft et al, 1997; Woelk et al, 2006), and these modifications are required

${ }^{1}$ IFOM, Fondazione Istituto FIRC (Fondazione Italiana per la Ricerca sul Cancro) di Oncologia Molecolare, Milan, Italy ${ }^{2}$ Cogentech Società Benefit Srl, Milan, Italy ${ }^{3}$ Experimental Imaging Centre, Istituto di Ricovero e Cura a Carattere Scientifico, San Raffaele Scientific Institute, Milan, Italy ${ }^{4}$ IEO, Istituto Europeo di Oncologia IRCCS (Istituti di Ricovero e Cura a Carattere Scientifico), Milan, Italy ${ }^{5}$ Università degli Studi di Milano, Dipartimento di Oncologia ed Emato-oncologia, Milan, Italy

${ }^{6}$ Dipartimento di Medicina Sperimentale, Università degli Studi di Genova, Genoa, Italy 
to assist during EGFR-CME (Torrisi et al, 1999; Confalonieri et al, 2000; Savio et al, 2016).

At the organismal level, studies in Caenorhabditis elegans and Drosophila melanogaster, where only one gene of the eps15 family exists, indicate that EPS15 plays an essential function in the nervous system, regulating synaptic vesicle recycling (SVR) (Salcini et al, 2001; Koh et al, 2007). The single Eps15 KO in mice, where both Eps15 and Eps15L1 exist, is viable and fertile. MEFs derived from these mice did not display defects in TfR endocytosis (Pozzi et al, 2012), suggesting that EPS15L1-which is expressed in this setting-possibly compensates the lack of EPS15. Their redundancy, however, has never been demonstrated in in vivo settings. Moreover, neither in vitro nor in vivo studies have so far revealed nonredundant essential functions. The present studies were undertaken to shed light on these questions.

\section{Results and Discussion}

\section{The Eps15L1-KO is perinatal lethal}

To investigate the functions of EPS15L1 at the organismal level, we generated Eps15L1-KO (Eps15L1-KO) mice by deleting the first coding exon (Fig S1). Although deletion of Eps15, as previously reported, did not affect viability (Pozzi et al, 2012), only 10\% of the weaned pups were Eps15L1-KO (instead of the expected 25\%, Fig 1A), indicating that EPS15L1 is required for neonatal viability, albeit with incomplete penetrance. Eps15L1-KO mice were born at the expected Mendelian ratio and were indistinguishable from WT littermates. Following the litters directly after birth revealed that newborn Eps15L1-KO died within the first $2 \mathrm{~d}$ of birth (Fig 1B) without any obvious morphological defects. The neonatal lethality of Eps15L1-KO mice, at variance with Eps15-KO, indicated a unique nonredundant function for EPS15L1.

\section{EPS15L1 is preferentially expressed in the nervous system and the Eps15L1-KO displays neurological deficits}

The time of neonatal lethality of Eps15L1-KO mice and their normal in utero development was not immediately consistent with a cause of death because of failure of major organs, such as the heart, lungs, or kidneys (Turgeon \& Meloche, 2009). Thus, as an initial step towards the understanding of the nonredundant function of EPS15L1, we analyzed its tissue distribution versus EPS15. EPS15 was expressed at similar levels in most of the analyzed tissues (Fig S2A). EPS15L1, instead, displayed prominent expression in the brain and
A
o
0
0
0
0
0
0
0
0
0
0
0
0

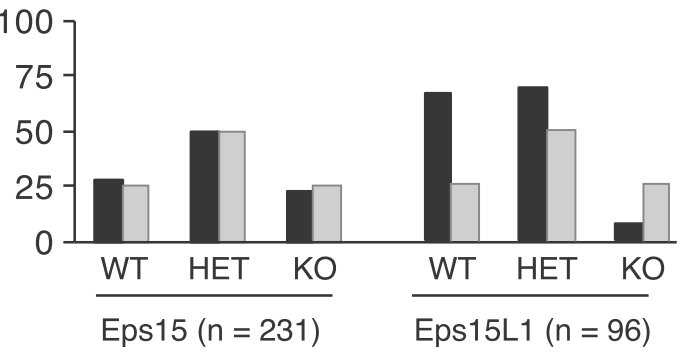

Obtained

Expected

B

吕

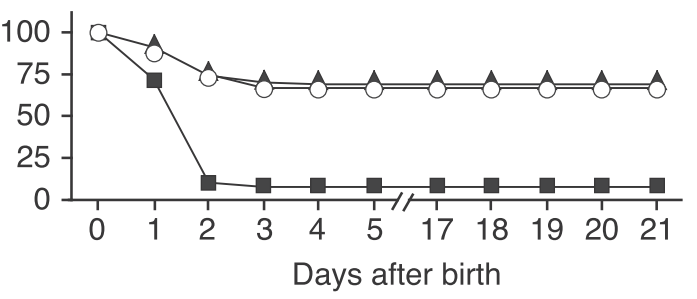

O Eps15L1-WT $(\mathrm{n}=40)$

$\Delta$ Eps15L1-HET $(\mathrm{n}=105)$

- Eps15L1-KO ( $\mathrm{n}=41)$

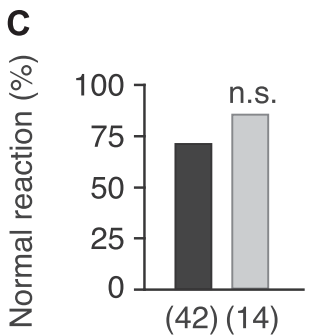

Tail suspension test

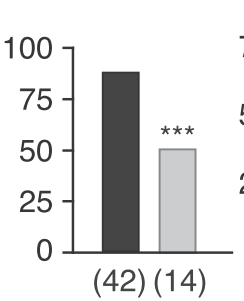

Tail flick test

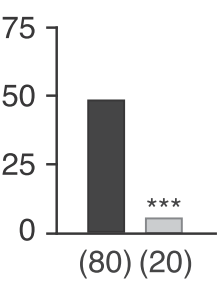

Feeding behavior
Figure 1. Eps15L1-KO mice are neonatal lethal.

(A) Percentage of expected (black bars) and obtained (grey bars) weaned pups of WT, heterozygous (HET), and KO genotype born from Eps15- or Eps15L1-HET breedings. (B) Percentage of surviving pups of WT, HET, and KO genotype after birth. The number of mice analyzed is shown in parentheses. (C) Percentage of normal reaction in the tail suspension, tail flick, feeding behavior, and respiratory behavior tests in Eps15L1-WT and Eps15L1-KO pups. The number of mice analyzed is shown in parentheses. n.s., not significant; ${ }^{* * *} P<0.001$ versus WT. 
cerebellum and comparatively lower levels in other tissues and MEFs (Fig S2B).

By immunofluorescence analysis of the hippocampus in adult mouse brain sections, both EPS15 and EPS15L1 localized to neurons, and EPS15 also showed substantial staining in cells with astrocytic morphology (Fig S2C). Of interest, EPS15L1 showed co-localization with synaptophysin, a presynaptic marker, whereas EPS15 did not (Fig $\mathrm{S} 2 \mathrm{C}$ ). This was further corroborated by a biochemical fractionation of adult mouse brain in which we compared the total homogenate $(\mathrm{H})$ to the synaptosomal fraction and to the postsynaptic density. Of the several endocytic proteins tested, EPS15L1 was the sole one clearly enriched in the synaptosomal fraction (marginal enrichment was also detected for dynamin and AP2; Fig S2D).

Based on the above results, we performed a series of neurological tests on newborn Eps15L1-KO (Fig 1C). We observed no difference in the tail suspension test, which assesses a reflex circuit involving the brainstem (Fig 1C). Conversely, in the nociceptive tail flick test, we scored a significant reduction of reactivity in Eps15L1-KO versus WT controls (Fig 1C). More importantly, we observed lack of feeding in 90\% of Eps15L1-KO pups, as evidenced by the absence of milk in their stomach, which represents the probable cause of death of these animals (Fig 1C). In addition, we observed difficulties in respiratory activity at the second day after birth in most of the Eps15L1-KO pups (Fig 1C), which might be either a primary defect or secondary to malnutrition. Of note, Eps15L1-KO mice that escaped perinatal death showed reduced growth rate (Fig S2E and F), neurological deficits (Fig S2G), and succumbed at 6-8 wk. In contrast, we have previously published that EPS15-KO mice do not show any neurological abnormality (Pozzi et al, 2012).

In summary, EPS15L1-in contrast to EPS15-is required for life in mice, possibly in conjunction with an essential nonredundant function of EPS15L1 in the nervous system.

\section{Evidence for a nonredundant role of EPS15L1 in synaptic function}

The sum of the above data and the lessons learned in model organisms (Salcini et al, 2001; Koh et al, 2007) prompted us to investigate a possible role for EPS15L1 in SVR. In the Drosophila model system, the ablation of eps15 was accompanied by a sizable decrease in the levels of dynamin and intersectin (Majumdar et al, 2006; Koh et al, 2007). Thus, we initially assessed the levels of a panel of endocytic proteins in the brain of newborn Eps15-KO and Eps15L1-KO mice. We observed no differences in the levels of expression of most of the proteins, including the core components of the endocytic machinery: AP2, dynamin, and clathrin (Fig 2A). An $\sim 50 \%$ decrease in the levels of intersectin-1 was detected in Eps15L1-KO mice (Fig 2A and B). This reduction appears to be specific for intersectin-1, as other presynaptic (e.g., synapsin, synaptophysin, and VGAT) or postsynaptic (e.g., GluR1) markers did not significantly change between Eps15L1-KO and Eps15L1-WT mice (Fig 2A and B). We concluded that the KO of either Eps15L1 or Eps15 does not have a general impact on the expression levels of the synaptic proteins.

Next, we performed an FM dye-based SVR assay on mature neurons cultured for $14 \mathrm{~d}$ in vitro. Fluorescence was measured after a first depolarization in the presence of the dye induced by $\mathrm{KCl}(\mathrm{F} 1$,
Fig 2 C, left) and then again after a second depolarization (F2, Fig 2C, left) to measure dye release from synaptic vesicles. We did not detect any significant difference in either F1 or F2, arguing for no apparent defects in SVR (Fig 2C, right). However, compensatory endocytic mechanisms might mask a defect in classical SVR (Nguyen et al, 2014); thus, we proceeded with an ultrastructural analysis of Eps15L1-KO neurons. We detected a reduction of synaptic vesicles in Eps15L1-KO synapses of about 50\%, although synapses from Eps15-KO were comparable with WT (Fig 2D). The number of docked/ tethered vesicles was also significantly decreased in Eps15L1-KO synapses (Fig 2E). This result is reminiscent of similar defects evidenced in model organisms (Salcini et al, 2001; Koh et al, 2007) and suggested that defective synaptic function may be responsible for the neurological deficits of Eps15L1-KO mice and possibly for neonatal lethality.

To test whether the absence of evident phenotypes in the dye uptake assay was due to the up-regulation of compensatory bulk endocytosis, we measured by EM the number of vesicles with a diameter higher than $80 \mathrm{~nm}$, as bulk endocytosis is typically characterized by large invaginations of the plasma membrane which then fission to form endosomal-like compartments (Cousin, 2009; Saheki \& De Camilli, 2012). Under steady state conditions, we did not observe differences in the number of this type of vesicles (Fig 2F). However, when we followed HRP uptake upon depolarization with $50 \mathrm{mM} \mathrm{KCl}$ (Fig 2G, left), we observed a significant increase in large HRP-positive structures in Eps15L1-KO neurons (Fig 2G, center and right), suggesting that bulk endocytosis is indeed more active in these cells.

\section{EPS15 and EPS15L1 are redundantly essential in embryonic development}

To investigate possible organismal redundant roles for EPS15 and EPS15L1, we generated Eps15/Eps15L1-double KO (DKO) mice by inter-crossing Eps15-KO/Eps15L1-HET. DKO embryos died shortly after $9.5 \mathrm{~d}$ post coitum (dpc) (Fig 3A), and already at $9.5 \mathrm{dpc}$, they showed severe morphological defects. Some of them presented severe developmental delay; all embryos, instead, displayed reduced midbrain-hindbrain boundary, fused somites, absence of limb bud, and delayed turning of the heart. Moreover, DKO embryos appeared paler than their controls (Fig 3B), possibly because of reduced vascularization or a defect in hematopoiesis, or both. PECAM staining of the vascular system effectively evidenced a reduced vascularization both of the embryo proper as well as of the yolk sac (Fig 3C and D). A more detailed confocal analysis of the PECAM staining confirmed the reduced and compromised vascularization of the head, somites, and yolk sac (Fig 3E) of DKO embryos.

To further characterize the vascular phenotype, we generated mice in which Eps15L1 was constitutively deleted and Eps15 was conditionally deleted under the Tie2 promoter (Eps15 flp/flp $/$ Eps15L1 ${ }^{-/-}$/ Tie2-Cre ${ }^{t g}$, referred to as conditional Eps15-KO/constitutive Eps15L1KO, C15/L1KO). These mice displayed only a mild vascular defect (data not shown), suggesting that the severe phenotype observed in constitutive DKO mice was not due to a cell-autonomous defect of endothelial cells. 
A

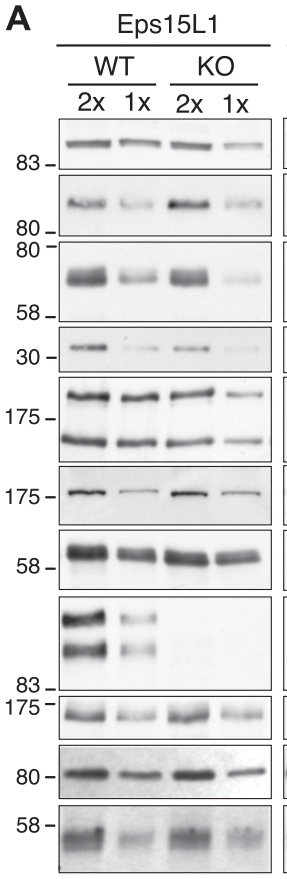

E

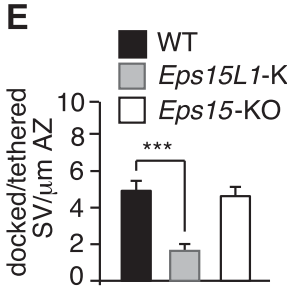

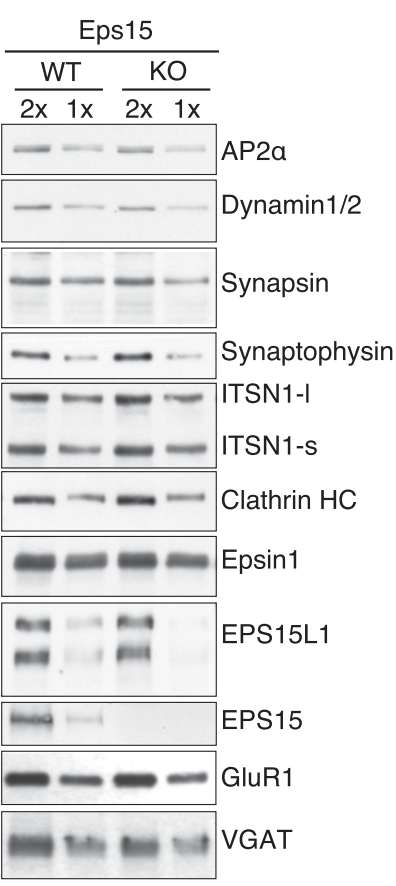

F

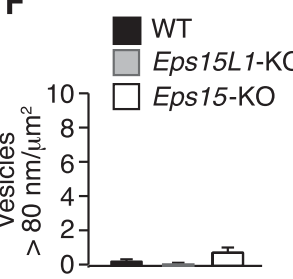

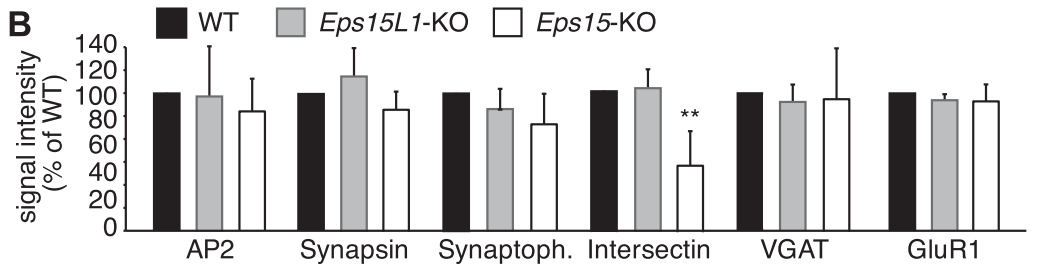

C
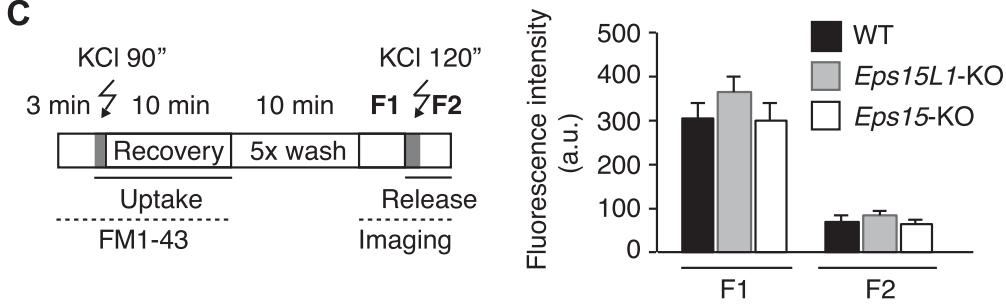

D
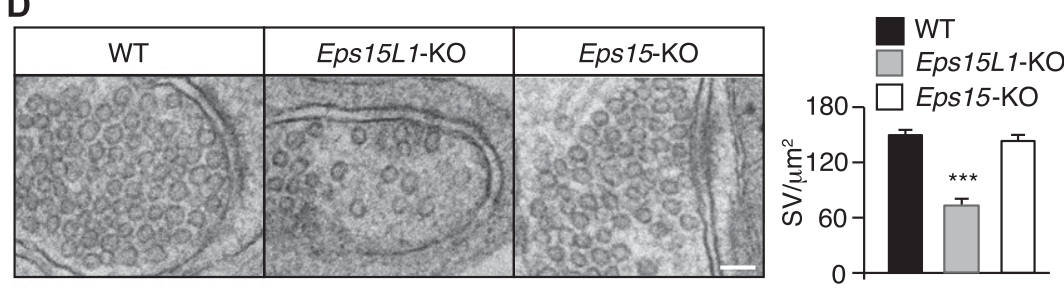

G
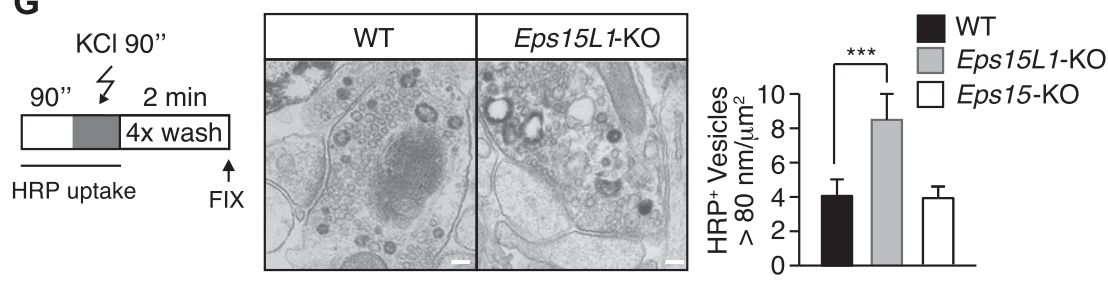

Figure 2. EPS15L1 has a nonredundant role in neurons.

(A) Western blotting of the indicated proteins in brain lysates from the indicated stains (neonatal mice). In the brain, two isoforms for intersectin-1 are present (ITSN1-I refers to the long isoform and ITSN1-S refers to the short isoform). Clathrin HC refers to clathrin heavy chain. Reduction of synaptophysin in Eps15L1-KO mice might be linked to a reduction in synapses, as observed in Drosophila eps15 mutants (Koh et al, 2007); the reduction of intersectin-1, which directly interacts with EPS15L1, instead, might indicate a destabilization of the protein when it is not complexed. (B) A quantitation of the results shown in A is depicted, as obtained from replica experiments $(n=2-3)$. Results are the mean \pm SD and are expressed as \% of signal in WT sample, normalized for the loading control (vinculin). (C) Left, schematic representation of the experimental setup for FM dye uptake and release from hippocampal neurons. Grey boxes indicate KCl pulses. Right, averaged fluorescence intensity in WT, Eps15L1-KO, and Eps15-KO neurons after dye uptake (F1) and after depolarization with $50 \mathrm{mM} \mathrm{KCl}$ and release (F2). Differences among genotypes are not significant. (D) Left, ultrastructural analysis of steady-state synapses from WT, Eps15L1-KO, and Eps15-KO hippocampal neurons. Bar, 100 nm. Right, quantitation of synaptic vesicles (SV) per area by ultrastructural analysis. At least three different preparations of neurons were analyzed; ${ }^{* *} P<0.001$ versus WT. (E) Quantitation of docked/tethered SV per length of active zone EM. At least three different preparations of neurons were analyzed; ***P<0.001 versus WT. (F) Quantitation of vesicles with diameter higher than $80 \mathrm{~nm}$ (SV) per $\mu \mathrm{m}^{2}$ by EM. At least three different preparations of neurons were analyzed. Differences among genotypes are not significant. (G) Left, schematic representation of the experimental setup for HRP uptake from hippocampal neurons. The grey box indicates the KCl pulse. Center, exemplary images by EM of HRP-labelled synapses from WT and Eps15L1-KO hippocampal neurons. Bar, $100 \mathrm{~nm}$. Right, quantitation of HRP-positive (HRP ${ }^{+}$) vesicles with diameter higher than $80 \mathrm{~nm}(\mathrm{SV})$ per $\mu \mathrm{m}^{2}$ by EM. ${ }^{* *} \mathrm{P}<0.001$ versus WT.

Source data are available for this figure.

\section{Deletion of Eps15 and Eps15L1 in the hematopoietic system affects maturation of RBCs}

We sought to identify a cellular function redundantly regulated in a cell-autonomous fashion by EPS15 and EPS15L1 at the organismal level. We concentrated on erythrocyte maturation for a series of reasons: (i) the pallor of the Eps15/Eps15L1-DKO mice; (ii) the redundant impact of EPS15 and EPS15L1 on TfR internalization ([Huang et al, 2004] and Fig 4A); (iii) the known role of TfR internalization in erythrocyte maturation (Levy et al, 1999; Zhu et al, 2008; Ishikawa et al, 2015; Muckenthaler et al, 2017); and (iv) the availability of c15/L1KO mice.
First, we investigated the expression of EPS15 and EPS15L1 during erythrocyte maturation. Mice were treated with phenylhydrazine ( $\mathrm{PHZ}$ ) to induce hemolytic anemia and formation of immature RBCS (Fig S3A and B). Consistent with a role in maturation of RBCS, we observed high levels of expression of EPS15 and EPS15L1 at the peak of immature RBCs (7-10 d after PHZ treatment), which dramatically decreased at $16 \mathrm{~d}$ (Fig S3C). The same kinetics were observed for TfR, intersectin-1, and AP2, compatible with a role for all these proteins in determining the wave of TfR required for maturation of RBCs (Fig S3C).

We then turned to the $\mathrm{C15} / \mathrm{L} 1 \mathrm{KO}$ mice. Analysis of the peripheral blood of newborn C15/L1KO mice revealed a significant reduction 
A

\begin{tabular}{cccccc}
\hline $\mathrm{dpc}$ & litters & $\begin{array}{c}\text { Eps15-KO/ } \\
\text { Eps15L1-WT }\end{array}$ & $\begin{array}{c}\text { Eps15-KO/ } \\
\text { Eps15L1-HET }\end{array}$ & $\begin{array}{c}\text { Eps15-KO/ } \\
\text { Eps15L1-KO }\end{array}$ & total \\
\hline 9.5 & 19 & $39(27 \%)$ & $75(53 \%)$ & $28(20 \%)$ & 142 \\
10.5 & 2 & $1(7 \%)$ & $11(78 \%)$ & $2(14 \%)$ & 14 \\
$11.5-12.5$ & 3 & $12(41 \%)$ & $15(52 \%)$ & $0(0 \%)^{*}$ & 29 \\
\hline
\end{tabular}

* 2 dead embryos

C

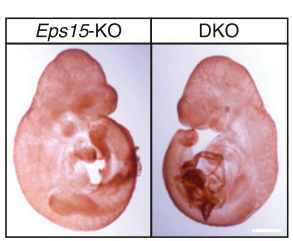

D

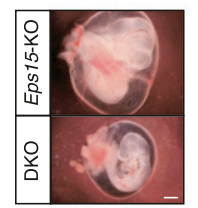

B

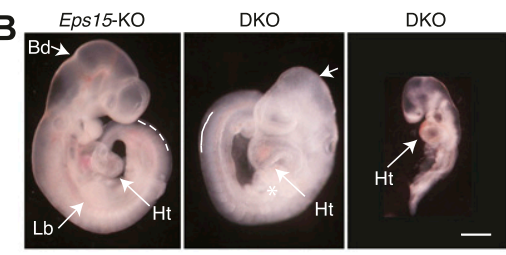

E

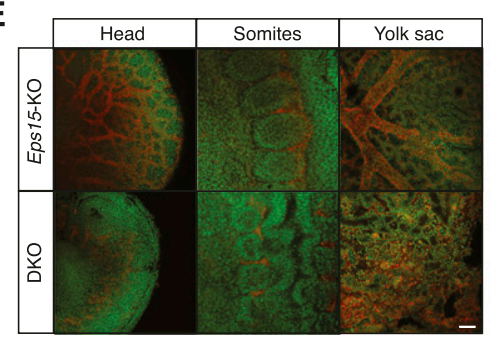

Figure 3. EPS15 and EPS15L1 are redundantly essential in embryonic development.

(A) Absolute and percent numbers of live embryos of the indicated genotypes, observed between 9.5 and $12.5 \mathrm{dpc}$. (B) Eps15-KO and DKO fresh embryos at $9.5 \mathrm{dpc}$. Arrows point to the limb bud ( $\mathrm{Lb})$, the midbrain-hindbrain boundary (Bd) and the heart ( $\mathrm{Ht})$. The star and the continuous lines indicate, respectively, the absence of limb bud and the presence of fused somites in DKO embryos, as compared with Eps15-KO mice where somites are not fused (indicated with dotted line). Some DKO embryos had a more severe phenotype and reduced size than others. Bar, $1 \mathrm{~mm}$. (C) Eps15-KO and DKO embryos at 9.5 dpc stained with anti-PECAM. Bar, $1 \mathrm{~mm}$. (D) Eps15-KO and DKO embryos and yolk sacs at $9.5 \mathrm{dpc}$ stained with anti-PECAM. Bar, $1 \mathrm{~mm}$. (E) Confocal images of head, somites, and yolk sac from Eps15-KO and DKO embryos at $9.5 \mathrm{dpc}$, stained with anti-PECAM (red). Nuclei were counterstained with TOPRO (green). Bar, $100 \mu \mathrm{m}$. of the mean corpuscular volume (MCV) and an increase in RBC distribution width, a value typically high in iron-deficient anemia (Fig 4B). Mice in which only Eps15 was deleted under the Tie2 promoter (Eps15 flp/flp $/$ Tie2-Cre ${ }^{\text {tg }}$, referred to as conditional Eps15$\mathrm{KO}, \mathrm{C} 15 \mathrm{KO}$ ) displayed a minor, if any, reduction in $\mathrm{MCV}$, whereas constitutive single Eps15L1-KO (L1KO) had no phenotype. Finally, May-Grünwald-Giemsa staining revealed the presence of anisotropic RBCs and a significant increase in reticulocyte number specifically in C15/L1KO mice (Fig 4C and D).

To analyze adult hematopoiesis, we generated mice in which both Eps15 and Eps15L1 were conditionally deleted under the Tie2 promoter (Eps15 flp/flp /Eps15L1 flp/flp/Tie2-Cretg , conditional Eps15/ Eps15L1-DKO, referred to as CDKO). Western blotting analysis on major tissues (the brain, liver, and spleen) confirmed that Eps15 and Eps15L1 were deleted in Tie2 ${ }^{+}$cells (Tang et al, 2010) of cDKO mice (Fig S3D). Adult cDKO mice were anemic as revealed by significant reduction of all analyzed parameters (Fig 4E). May-GrünwaldGiemsa staining revealed a great variation in the size and shape of CDKO RBCs (Fig 4F, top). Finally, o-dianisidine staining clearly showed that RBCs from CDKO were hypochromic (Fig 4F, bottom; additional characterizations of iron metabolism, in CDKO mice, are shown in Fig S3E and F). Thus, CDKO mice suffer from microcytic hypochromic anemia (Levy et al, 1999; Zhu et al, 2008; Ishikawa et al, 2015).

\section{EPS15 and EPS15L1 redundantly regulate TfR internalization in RBCs}

In search of a molecular explanation for the RBC phenotype in CDKO mice, we concentrated on TfR endocytosis. We reasoned that the phenotype of cDKO (impaired maturation of RBCS and increased serum iron) could be explained by defective iron uptake through TfR endocytosis in RBCs of these mice. To discriminate mature RBCs from reticulocytes, we used thiazole orange (TO) to detect the nucleic acids in immature RBCs. Consistent with defective erythrocyte maturation, we detected twice as many reticulocytes (TO-positive cells, $\left.\mathrm{TO}^{+}\right)$in the blood of cDKO $(5.5 \pm 0.4$ in WT versus $10.7 \pm 1.5$ in $C D K O, P<0.001$ [Fig 4G, top]). In addition, surface TfR expression was retained in $\sim 50 \%$ of mature RBCS (TO-negative cells, $\mathrm{TO}^{-}$) in (DKO mice, whereas it was virtually absent-as expected-in WT mice (Fig 4G, bottom, and H). Finally, in cDKO mice, a significantly higher fraction of $\mathrm{TO}^{+}$retained TfR surface expression versus the WT counterparts (Fig $4 G$, bottom, and $H$ ).

\section{Redundancy and uniqueness of EPS15 and EPS15L1}

We have herein characterized a number of redundant and nonredundant functions of EPS15 and EPS15L1 at the organismal level in mice.

In our previous work, we showed that Eps15-KO mice are viable and fertile and, notwithstanding extensive phenotype screening, showed only a partial defect in B-cell lymphopoiesis (Pozzi et al, 2012). At variance, we show here that Eps15L1-KO mice show readily detectable neurological defects, associated with reduced number of synaptic vesicles, and neonatal lethality. We have not proved that the neonatal phenotype is a direct consequence of the neurological defect and of altered SVR. Neuronal-specific conditional KO will be needed to address this issue. However, we note that the depletion in synaptic vesicles detected in Eps15L1-KO mice is highly reminiscent of the phenotypes observed in the nematode and in flies, upon deletion of the sole orthologue of Eps15 in these species. In these latter cases, it was established that the SVR phenotype was responsible for the neurological defects and, in the case of Drosophila, for lethality (Salcini et al, 2001; Koh et al, 2007).

Our studies also allowed the identification of a number of redundant functions of Eps15 and Eps15L1. These two genes are required (redundantly) for correct embryo development. The severity and complexity of the phenotype argues for the possibility that not a single but a multitude of signaling pathways is affected in these mice: a possibility compatible with the role of these proteins in a pervading process such as endocytosis. At the phenotypic level, one major alteration, which might contribute importantly to the lethal phenotype of DKO embryos, was subverted angiogenesis. This phenotype, however, was non-cell autonomous, and its exact mechanism remains to be elucidated.

One redundant function that we were able to precisely dissect, both cellularly and molecularly, concerns erythropoiesis. Here, we 


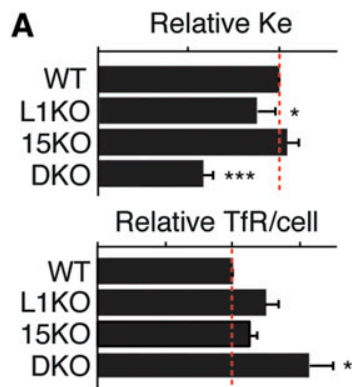

\begin{tabular}{|l|c|c|c|c|c|}
\cline { 2 - 6 } \multicolumn{1}{c|}{$B$} & $\begin{array}{c}\mathrm{RBCs} \\
\left(\mathrm{x} 10^{6} / \mu \mathrm{L}\right)\end{array}$ & $\begin{array}{c}\mathrm{HGB} \\
(\mathrm{g} / \mathrm{dL})\end{array}$ & $\begin{array}{c}\mathrm{HCT} \\
(\%)\end{array}$ & $\begin{array}{c}\mathrm{MCV} \\
(\mathrm{fL})\end{array}$ & $\begin{array}{c}\text { RDW } \\
(\%)\end{array}$ \\
\hline WT & $2.8 \pm 0.2$ & $9.0 \pm 0.9$ & $25.9 \pm 1.9$ & $92.5 \pm 0.9$ & $14.6 \pm 0.3$ \\
\hline L1KO & $2.9 \pm 0.3$ & $9.4 \pm 1.1$ & $26.9 \pm 2.7$ & $93.5 \pm 0.8$ & $13.9 \pm 0.7$ \\
\hline c15KO & $2.9 \pm 0.2$ & $9.4 \pm 0.8$ & $27.4 \pm 1.4$ & $\begin{array}{c}89.0 \pm 0.6 \\
(* \star)\end{array}$ & $14.9 \pm 0.3$ \\
\hline $\begin{array}{c}\text { c15/ } \\
\text { L1KO }\end{array}$ & $2.3 \pm 0.3$ & $6.6 \pm 0.6$ & $19.9 \pm 2.4$ & $\begin{array}{c}84.1 \pm 1.1 \\
(* \star *)\end{array}$ & $\begin{array}{c}18.4 \pm 1.2 \\
(\star \star *)\end{array}$ \\
\hline
\end{tabular}
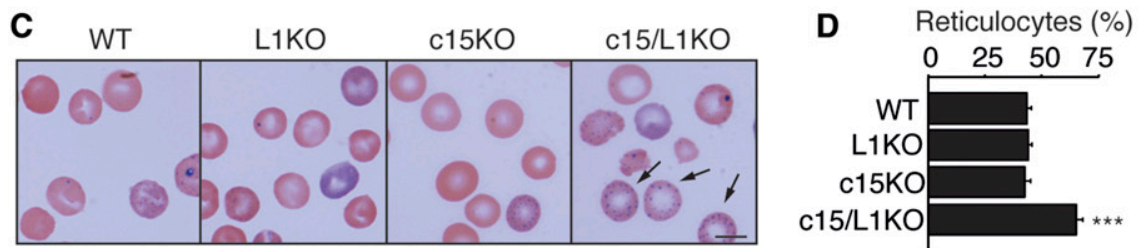

\begin{tabular}{|c|c|c|}
\cline { 3 - 3 } \multicolumn{1}{c|}{} & WT & $\mathrm{cDKO}$ \\
\hline $\begin{array}{c}\mathrm{RBCs} \\
\left(\mathrm{x} 10^{6} / \mu \mathrm{L}\right)\end{array}$ & $8.9 \pm 0.5$ & $\begin{array}{c}6.9 \pm 0.3 \\
(*)\end{array}$ \\
\hline $\begin{array}{c}\mathrm{HGB} \\
(\mathrm{g} / \mathrm{dL})\end{array}$ & $15.0 \pm 0.8$ & $\begin{array}{c}10.1 \pm 0.4 \\
(* \star)\end{array}$ \\
\hline $\begin{array}{c}\mathrm{HCT} \\
(\%)\end{array}$ & $42.2 \pm 2.3$ & $\begin{array}{c}22.4 \pm 0.9 \\
(* *)\end{array}$ \\
\hline $\begin{array}{c}\mathrm{MCV} \\
(\mathrm{fL})\end{array}$ & $47.4 \pm 1.0$ & $\begin{array}{c}32.7 \pm 1.2 \\
(* * *)\end{array}$ \\
\hline
\end{tabular}

G
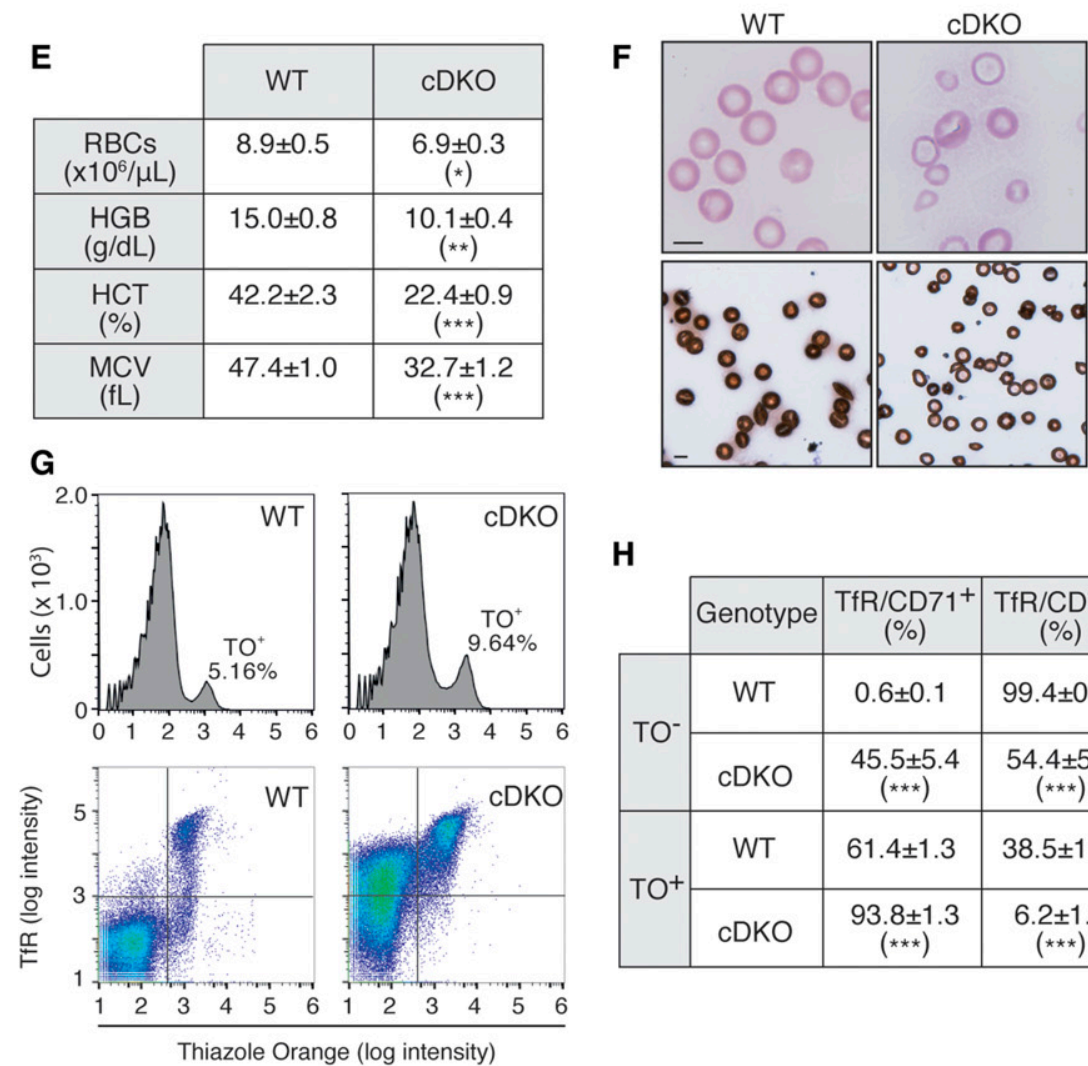

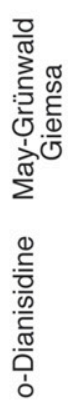

$\mathbf{H}$

\begin{tabular}{|c|c|c|c|}
\cline { 2 - 4 } \multicolumn{1}{c|}{} & Genotype & $\begin{array}{c}\text { TfR/CD71 } \\
(\%)\end{array}$ & $\begin{array}{c}\text { TfR/CD71- } \\
(\%)\end{array}$ \\
\hline \multirow{2}{*}{ TO- $^{-}$} & WT & $0.6 \pm 0.1$ & $99.4 \pm 0.1$ \\
\cline { 2 - 4 } & CDKO & $\begin{array}{c}45.5 \pm 5.4 \\
(* * \star)\end{array}$ & $\begin{array}{c}54.4 \pm 5.5 \\
(* * *)\end{array}$ \\
\hline \multirow{2}{*}{ TO $^{+}$} & WT & $61.4 \pm 1.3$ & $38.5 \pm 1.3$ \\
\cline { 2 - 4 } & CDKO & $\begin{array}{c}93.8 \pm 1.3 \\
(* \star *)\end{array}$ & $\begin{array}{c}6.2 \pm 1.3 \\
(* * *)\end{array}$ \\
\hline
\end{tabular}

Figure 4. Deletion of Eps15 and Eps15L1 in the hematopoietic system causes microcytic hypochromic anemia.

(A) Relative TfR endocytic constant ( $\mathrm{K}_{\mathrm{e}}$ ) (top) and TfR surface levels per cell (bottom) in WT, Eps15L1-KO (L1KO), Eps15-KO (15KO), and DKO fibroblasts. WT value $(=1.0)$ is shown by a dashed red line. (B) Values of RBCS, hemoglobin (HGB), hematocrit (HCT), MCV, and RBC distribution width in newborn WT, Eps15L1-KO (L1KO), conditional Eps15-KO (c15KO), and conditional Eps15KO/Eps15L1-KO (c15/L1KO) mice. At least eight animals for each genotype were analyzed. (C) May-Grünwald-Giemsa staining of blood smears from newborn mice of the indicated genotype. Arrows point to reticulocytes, which retain methylene blue dye. Bar, $10 \mu \mathrm{m}$. (D) Quantitation of the experiments shown in (C). Number of newborn mice analyzed: $\mathrm{WT}=7$, L1KO $=6$, $\mathrm{C} 15 \mathrm{KO}=6, \mathrm{C15} / \mathrm{L} 1 \mathrm{KI}=6$. (E) Values of RBCS, HGB, HCT, and $M C V$ in adult WT and CDKO mice. At least nine animals of each genotype were analyzed. (F) Blood smears of adult WT and CDKO mice stained with May-Grünwald-Giemsa (top) or o-dianisidine (bottom). Bar, $10 \mu \mathrm{m}$. (G) Representative fluorescence-activated cell sorting (FACS) analysis of peripheral blood from adult WT and CDKO mice, stained with thiazole orange (TO) to reveal reticulocytes (top) or with TfR (CD71) and thiazole orange for nucleic acids (bottom). In the top panels, the percentage of $\mathrm{TO}^{+}$cells in one representative WT and in one representative CDKO is shown. In the main test, average $\pm \mathrm{SEM}$ of $\mathrm{TO}^{+}$cells, calculated from at least five animals of each genotype, is indicated. $(\mathbf{H})$ Percentage of positive and negative RBCs for surface TfR (CD71) among $\mathrm{TO}^{+}$and $\mathrm{TO}^{-}$blood cells, in adult WT and CDKO mice. At least five animals of each genotype were analyzed. In (A), (B), (D), (E), and $(H):{ }^{*} P<0.05$ versus $W T ;{ }^{*} P<0.01$ versus WT; ${ }^{\star \star \star} P<0.001$ versus WT. showed that EPS15 and EPS15L1 are redundantly required for the internalization of the TfR, which at the organismal level leads to microcytic hypochromic anemia when lacking in the hematopoietic system. These results are reminiscent of those obtained in hematopoietic-specific KO mice for PICALM, an accessory endocytic adaptor and binding partner of EPS15 and EPS15L1. These mice suffered from microcytic hypochromic anemia, displaying reduced RBCS, haemoglobin, haematocrit, and MCV, and increased reticulocyte number and serum iron (Ishikawa et al, 2015). Moreover, also in these mice, anemia was caused by defective TfR internalization in RBCs.
Evolutionarily, the duplication of the ancestral Eps15 locus must have occurred in a vertebrate ancestor, within metazoan, because all vertebrates display two orthologues, whereas invertebrates possess only one (Fig S3G). By analyzing comparatively the results in invertebrates (Salcini et al, 2001; Koh et al, 2007) and in mammals ([Pozzi et al, 2012] and this study), it is likely that the essential functions of proto-EPS15 were retained by EPS15L1, whereas EPS15 diverged to assume more fine-tuning roles, while retaining a large (albeit not complete) spectrum of redundancy with EPS15L1. This possibility is supported by the 
closer similarity of vertebrate EPS15L1s with the invertebrate orthologues and by the slower rate of divergence of this gene versus EPS15, during vertebrate radiation (Fig S3G). The high degree of similarity and collinearity between the two genes/ proteins should now enable structure-function experiments to unmask the structural determinant responsible for the unique function of EPS15L1 in neurons.

\section{Materials and Methods}

\section{Generation and maintenance of mouse strains}

The Eps15-KO was previously described (Pozzi et al, 2012). The conditional Eps15-KO allele (Eps15 ${ }^{\text {tm1a(KOMP)Wtsi }}$, in the text referred to as Eps $15^{f l p / f l p}$ ) was obtained from the Sanger Institute. The PGKneo cassette was removed by breeding to general deleter Flp mice and the Flp transgene was removed in subsequent breedings. The Eps15L1-KO was generated in a C57BL6 background by Ozgene, through insertion of a PGK-neo cassette next to the first coding exon. The first exon and the PGK-neo cassette were removed by crossing with general deleter Cre mice and the Cre transgene was removed in subsequent breedings. The conditional Eps15L1-KO allele (Eps15Lfflp/flp) was obtained from Polygene. The PGK-neo cassette was removed by breeding to general deleter Flp mice and the Flp transgene was removed by subsequent breedings.

For isolation of MEFs, Eps15 flp/flp mice were crossed with Eps15L $1^{+/-}$

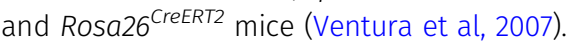

For hematological studies, Eps15flp/flp mice were crossed with Eps15L1 $1^{+/-}$or Eps15L1 flp/flp and Tie2-Cre ${ }^{\text {tg }}$ mice (Kisanuki et al, 2001) to obtain deletion of the floxed genes in endothelial and hematopoietic cells.

Mice were kept on $12 \mathrm{~h}$ light/dark cycle with ad libitum access to water and food. Experiments were performed in accordance with our institution guidelines and the Italian Laws (Project numbers: 06/12 and 222/16).

\section{Behavioral test}

Neonatal behavior tests were scored giving either a normal or abnormal evaluation to the observed phenotype. To evaluate neonatal motor and nociception functions, pups were subjected to the tail suspension and the tail flick test, respectively (Sternberg et al, 2004; Takahashi et al, 2010).

In the tail suspension test, the pup was gently held by the tip of the tail and the position observed recorded. A normal reaction was scored when the pup was hanging symmetrically with all four limbs wide open. The test was scored as abnormal if the hind limbs were touching or clasping during the test.

In the tail flick test, the pup was held between the thumb and forefinger in an upright position and the distal tip of the tail was gently lowered into a water bath maintained at $50^{\circ} \mathrm{C}$. The latency to vigorous tail withdrawal was recorded, with a 15 -s cutoff time. The test was repeated after a 30-s interval and the latencies were averaged. Tail withdrawl within $15 \mathrm{~s}$ was scored as normal, whereas longer retraction times were scored as abnormal.
The feeding status was estimated at the day of birth by carefully observing the pups for the presence of milk in the stomach, which is visible through the thin abdominal skin of pups.

The respiration behavior was assessed by visual examination. Apneas, sighs, gasps, paroxysmal, or periodic breathing were considered as pathological. All tests were performed in blind respect to the genotype of the animals.

\section{Primary culture of hippocampal neurons}

Primary neurons were isolated from hippocampi dissected from PO newborn mice and placed in cold HBSS buffer. Digestion of the hippocampi was performed at $37^{\circ} \mathrm{C}$ in water bath for $10 \mathrm{~min}$ using papain (20 U/ml final) in EBSS buffer with the addition of DNase $(500 \mathrm{U} / \mathrm{ml}$ final) (all from Worthington Biochemical Corporation). After trituration of the solution, the cell pellet was washed two times in EBSS and resuspended in Neurobasal-A medium supplemented with B27, GlutaMAX, and antibiotics (all from Life Technologies). The cells were plated onto glass coverslips or glass bottom dishes (MatTek Corporation) coated with $1 \mathrm{mg} / \mathrm{ml}$ poly-D-lysine hydrobromide (Sigma-Aldrich). Primary cultures from hippocampal neurons were used at $14 \mathrm{~d}$ from their isolation.

\section{Dye uptake experiments}

For dye uptake experiments, FM1-43 dye (Molecular probes from Life Technologies) was used at a concentration of $1 \mu \mathrm{m}$. Recovery buffer contained $130 \mathrm{mM} \mathrm{NaCl}, 5 \mathrm{mM} \mathrm{KCl}, 2 \mathrm{mM} \mathrm{CaCl}, 2 \mathrm{mM} \mathrm{MgCl}$, $25 \mathrm{mM}$ Hepes ( $\mathrm{pH}$ 7.33), and $30 \mathrm{mM}$ glucose. Stimulation buffer contained as above except for $85 \mathrm{mM} \mathrm{NaCl}$ and $50 \mathrm{mM} \mathrm{KCl}$.

DL-2-amino-5-phosphonopentanoic acid (AP-V; Sigma-Aldrich), CNQX (Ascent Scientific), and sodium kynurenate (Ascent Scientific) were added to all solutions, except HBSS, at the final concentration of $50 \mu \mathrm{M}, 100 \mu \mathrm{M}$, and $1 \mathrm{mM}$, respectively.

Dye uptake experiments of primary hippocampal neurons were performed at room temperature as follows: the cells were incubated 3 min in recovery buffer with dye and then stimulated with stimulation buffer with dye for $90 \mathrm{~s}$, following 10 min in recovery buffer with dye. After 10 min of several washes in HBSS buffer (Life Technologies), neurons were bathed for 2 min in HBSS with $10 \mathrm{mM}$ ADVASEPT (Sigma-Aldrich) and washed two times with HBSS alone. For acquisition of microscope images, neurons were placed in recovery buffer (without dye) and stimulated with stimulation buffer (without dye).

Fluorescence microscopy was performed on an UltraVIEW VoX (Perkin Elmer) spinning disk confocal unit, equipped with an Eclipse Ti inverted microscope (Nikon), a C9100-50 emCCD camera (Hamamatsu), and driven by Volocity software (Improvision, Perkin Elmer). Images were acquired with a $60 \times$ oil immersion objective (NA 1.4) as Z-stacks (0.3 $\mu \mathrm{m}$ step). F1 stacks (dye uptake) were acquired while neurons were in the recovery buffer. F2 stacks (after dye release) were taken after 2 min from the application of the stimulation buffer.

Images were analyzed using ImageJ software (ImageJ 1.43u) as follows: F1 and F2 Z-stacks were transformed in single images using the max intensity tool and subsequently concatenated. 
The resulting F1-F2 stack was aligned and the background was subtracted. Fluorescence intensity (F1 and F2) of single punctuated signals was automatically calculated using a homemade macro.

\section{Electron microscopy and morphometry}

Conventional electron microscopy was carried out as previously described (Polishchuk et al, 1999; Beznoussenko et al, 2007). Hippocampal neuron cultures were directly fixed with $1 \%$ glutaraldehyde in $0.2 \mathrm{M}$ Hepes ( $\mathrm{pH}$ 7.2-7.4). The number of vesicles (i.e., synaptic vesicles, docked/tethered or vesicles larger than $80 \mathrm{~nm}$ ) was determined on electron micrographs with ImageJ software (ImageJ 1.43u) and a homemade ImageJ script. Synaptic vesicles were defined as the small homogenously sized vesicles $(\leq 60 \mathrm{~nm})$ forming large clusters in the terminal. Docked/tethered vesicles were defined as small homogenously sized vesicles $(\leq 60 \mathrm{~nm})$ within $25 \mathrm{~nm}$ from the active zone PM. For bulk steady-state endocytosis, we measured vesicles larger than $80 \mathrm{~nm}$ in the terminal. For HRP uptake experiments, peroxidase from horseradish Type $\mathrm{VI-A}$ (Sigma-Aldrich) was used at concentration of $10 \mathrm{mg} / \mathrm{ml}$. All buffers with inhibitors were the same as for the "dye uptake experiments" described above. Neurons were allowed to equilibrate for $90 \mathrm{~s}$ in the recovery buffer with HRP, and then stimulated for $90 \mathrm{~s}$ with the stimulation buffer with HRP. After four quick washes with the recovery buffer, the neurons were fixed with $2.5 \%$ glutaraldehyde/0.1 M cacodylate, $\mathrm{pH} 7.4$.

Images were analyzed using ImageJ software (ImageJ 1.43u). The number of HRP-positive vesicles larger than $80 \mathrm{~nm}$ was automatically calculated using a homemade ImageJ Script. Statistical significance was calculated by $t$ test.

\section{Whole-mount staining of Eps15/Eps15L1-DKO embryos with anti-PECAM primary antibody}

Embryos were collected at $9.5 \mathrm{dpc}$ and fixed overnight at $4^{\circ} \mathrm{C}$ in $100 \%$ methanol. After fixation, the embryos were rehydrated and blocked overnight at $4^{\circ} \mathrm{C}$ in PBS containing $5 \%$ donkey serum, $1 \%$ BSA, and $0.5 \%$ Triton-X 100. After wash, they were incubated overnight at $4^{\circ} \mathrm{C}$ with anti-PECAM primary antibody (kindly provided by E. Dejana) in PBS containing 0.5\% BSA and 0.25\% Triton-X 100. The primary antibody was revealed by VECTASTAIN ABC system (Vectorlabs), according to the manufacturer's instructions, and images acquired under a Leica stereo microscope. Alternatively, PECAM was revealed by immunofluorescence as follows: embryos were incubated with anti-rat Alexa 488 and TOPRO (Thermo Fisher Scientific) in PBS containing 0.5\% BSA and $0.25 \%$ Triton-X 100 for $2 \mathrm{~h}$ at room temperature. The embryos were then washed, post-fixed in 4\% paraformaldehyde, and mounted with ProLong Gold. Images were taken with a Leica TCS SP5 confocal microscope.

\section{Isolation of MEFs}

MEFs were isolated from Eps15 flp/flp $/$ Eps $15 \mathrm{L1}^{+/+} / \mathrm{CreERT2} 2^{\text {tg }}$ and

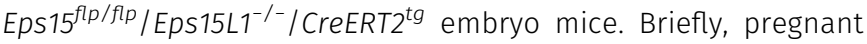
mice were euthanized at $13.5 \mathrm{dpc}$ by $\mathrm{CO}_{2}$ asphyxia. The embryos were decapitated for genotyping and the internal organs removed.
The embryos were then dissociated with a blade, transferred to $0.05 \%$ trypsin plus $0.02 \%$ EDTA solution, and incubated for $10 \mathrm{~min}$ at $37^{\circ} \mathrm{C}$ under agitation. After addition of $100 \mu \mathrm{g} / \mathrm{ml}$ DNase I (Roche), the embryos were incubated for further $10 \mathrm{~min}$. Digestion was completed by passing embryonic tissues through an 18-gauge needle. The cells were finally isolated through a $70-\mu \mathrm{m}$ cell strainer and plated in $10-\mathrm{cm}$ petri dishes. The cells were grown in Hepes buffered GlutaMAX-DMEM (Gibco Invitrogen) supplemented with $10 \%$ fetal bovine serum (HyClone), at $37^{\circ} \mathrm{C}$ and $9 \% \mathrm{CO}_{2}$.

\section{Radioactive internalization and saturation binding assay}

Radioactive internalization and saturation binding assay were performed as previously described (Sigismund et al, 2005). Experiments were performed on WT, EpS15L1-KO, Eps15-KO, and Eps15/Eps15L1-DKO MEFs. WT and Eps15-KO fibroblasts were derived from Eps15flp/flp $/ E p s 15 \mathrm{~L}^{+/+} / \mathrm{CreERT2}{ }^{\text {tg }}$ mice, after in vitro treatment with DMSO vehicle or $250 \mathrm{nM}$ (Z)-4-hydroxytamoxifen (SigmaAldrich), respectively. Eps15L1-KO and Eps15/Eps15L1-DKO fibroblasts were derived from Eps15 flp/flp $/$ Eps $15 \mathrm{~L}^{-1-} / \mathrm{CreERT2}^{\text {tg }}$ mice, after in vitro treatment with DMSO vehicle or $250 \mathrm{nM}$ (Z)-4-hydroxytamoxifen, respectively. At least three different preparations of cells were analyzed.

\section{Biochemical studies}

Dissection of the brains for immunofluorescence and fractionation of the brains for Western blotting was performed as previously described (Offenhauser et al, 2006).

Western blotting on whole tissue extracts and RBC lysates was performed as follows. Tissues (isolated after sacrifice of the mice by $\mathrm{CO}_{2}$ asphyxia) and peripheral RBCs (collected as explained in the next section) were washed in PBS and homogenized in a lysis buffer containing $50 \mathrm{mM}$ Hepes, pH 7.4, $150 \mathrm{mM} \mathrm{NaCl}$, 1\% glycerol, 1\% triton $\mathrm{X}-100,1.5 \mathrm{mM} \mathrm{MgCl}$, $5 \mathrm{mM}$ EGTA, $1 \mathrm{mM}$ PMSF, $10 \mathrm{mM}$ sodium orthovanadate, $50 \mathrm{mM}$ sodium fluoride, and protease inhibitor cocktail SetIII (Calbiochem). The lysates were then clarified at $4^{\circ} \mathrm{C}$ by centrifugation at 120,000 $\mathrm{g}$ for $1 \mathrm{~h}$ (for tissues) or 10,000 $\mathrm{g}$ for 15 min (for RBCs). Protein concentration was measured by BCA protein assay (Thermo Fisher Scientific), according to the manufacturer's instructions. Desired amounts of proteins were dissolved in Laemmli buffer (final concentration: $2 \%$ SDS, $50 \mathrm{mM}$ Tris- $\mathrm{HCl}, \mathrm{pH}$ 6.8, $100 \mathrm{mM}$ DTT, 10\% glycerol, and $0.001 \%$ bromophenol blue), boiled for $5 \mathrm{~min}$, separated by SDS-PAGE, and then transferred on nitrocellulose membranes. The membranes were blocked for $1 \mathrm{~h}$ in $5 \%$ BSA or 5\% low-fat dry milk (in TBS plus $0.1 \%$ Triton X-100) and then incubated overnight at $4^{\circ} \mathrm{C}$ with the primary antibody. After wash, the membranes were incubated with HRP-conjugated secondary antibody (Cell signaling) for $1 \mathrm{~h}$ at room temperature. The bound secondary antibody was revealed through chemiluminescence by photographic films (Amersham Hyperfilm ECL) or under a ChemiDoc Imaging System, after incubation with ECL substrate. Quantitation of the blots was performed using ImageJ (ImageJ 1.43u). The following primary antibodies were used: anti$\alpha$ adaptin (mouse monoclonal AP6; Thermo Fisher Scientific), anti-clathrin heavy chain (rabbit polyclonal \#4796; Cell Signaling), 
anti-dynamin1/2 (mouse monoclonal \#MABT188; EDM Millipore), homemade anti-EPS15 (mouse monoclonal 3T3), homemade antiEPS15L1 (rabbit polyclonal \#860), anti-epsin-1 (mouse monoclonal ZZ3, kindly provided by S. Polo), anti-intersectin-1 (rabbit polyclonal $\# 499$, kindly provided by S. Polo), anti-synapsin (rabbit polyclonal \#A6442; Thermo Fisher Scientific), anti-PSD95 (mouse monoclonal \#MA1-046; Affinity Bioreagents), anti-synaptophysin (mouse monoclonal \#101011 and rabbit polyclonal \#101002 Synaptic Systems), anti-GluR1 (rabbit polyclonal, \#06-306 Upstate), anti-VGAT (rabbit polyclonal, \#131013 Synaptic Systems), anti-TfR (mouse monoclonal \#H68.4; Thermo Fisher Scientific), anti-tubulin (mouse monoclonal \#T5168; Sigma-Aldrich), and anti-vinculin (mouse monoclonal \#V9131; Sigma-Aldrich).

\section{Collection and staining of blood smears}

To analyze protein expression during induced erythropoiesis, WT mice were treated with $1 \% \mathrm{PHZ}$ (Sigma-Aldrich) in sterile PBS at day $0(4 \mathrm{ml} / \mathrm{g})$ and at day $3(6 \mathrm{ml} / \mathrm{g})$. The animals were then monitored daily, and blood was collected at different time points, as reported in the text. For all hematological studies, the blood was collected after decapitation or by tail vein puncture. During collection, blood was transferred in an EDTA-containing solution at $100 \mathrm{mM}$ final concentration. The blood was analyzed in a hemocytometer (Beckman Coulter) and smeared on glass slides. For determination of reticulocytes, the blood smears were stained with reticulocyte stain (Sigma-Aldrich), based on methylene blue dye, or with May-Grünwald-Giemsa stain (Sigma-Aldrich), according to the manufacturer's instructions. For determination of intracellular hemoglobin, the blood smears were stained with o-dianisidine (Sigma-Aldrich), as described in Fibach \& Prus (2005). After staining, the blood smears were airdried and examined under a Leica stereo microscope, using a 100x oil immersion objective.

\section{FACS staining of RBCs}

After collection and dilution in an EDTA-containing solution, peripheral RBCs were washed with cold PBS and blocked for $1 \mathrm{~h}$ in PBS plus $10 \% \mathrm{BSA}$ at $4^{\circ} \mathrm{C}$. The cells were then incubated overnight at $4^{\circ} \mathrm{C}$ with anti-CD71 antibody conjugated to PE (BD) or APC (eBioscience) and diluted in PBS plus 1\% BSA. After wash, the cells were incubated with thiazole orange (BD) for $1 \mathrm{~h}$ at room temperature. The samples were acquired on a FACSCanto II (Becton Dickinson). Data were analyzed with Flowjo 10.1 software.

\section{Analysis of iron metabolism}

Serum iron levels were determined by MULTIGENT Iron assay (Abbott), according to the manufacturer's instructions. Serum transferrin and ferritin levels were determined with Transferrin Mouse ELISA kit (Abcam) and Ferritin Mouse ELISA kit (Abcam), respectively, according to the manufacturer's instructions.

\section{Perls' Prussian blue staining}

After sacrifice of the mice by $\mathrm{CO}_{2}$ asphyxia, the liver and spleen were isolated, washed in PBS, and fixed overnight in $4 \%$ paraformaldehyde. After paraffin-embedding, 3- $\mu$ m sections were cut. Staining was performed using Perls' Prussian blue stain kit (DDK Italia), according to the manufacturer's instructions. Examination was performed by digital imaging, using the Leica Aperio ScanScope scanning system. Representative images were extrapolated at 20× optical zoom.

\section{Statistical analysis}

For each experiment, the number of observations (number of animals or cellular culture preparations) is specified within figures or reported in the figure legends. All values are average \pm SEM, and differences were analyzed to detect statistical significance with a two-tailed $t$ test (n.s., not significant; ${ }^{\star} P<0.05$; ${ }^{* \star} P<$ $\left.0.01 ;{ }^{* * *} P<0.001\right)$.

\section{Study approval}

All animal studies were conducted with the approval of Italian Minister of Health (03/2008; 06/2012; 222/16) and were performed in accordance with the Italian law (D.lgs. 26/2014), which enforces Dir. 2010/63/EU (Directive 2010/63/EU of the European Parliament and of the Council of 22 September 2010 on the protection of animals used for scientific purposes).

\section{Supplementary Information}

Supplementary Information is available at https://doi.org/10.26508/lsa. 201800273.

\section{Acknowledgements}

We thank Rosalind Gunby for critically reading the manuscript. We thank Dr Simona Polo (IFOM, Milan) for generously providing antisera against intersectin. We are grateful to Alberto Gobbi, Emanuela Capillo, and the Mouse facility (Cogentech Società Benefit Srl, Milan). We thank the Imaging facility at IFOM/Cogentech Società Benefit Srl, Milan, and the ALEMBIC facility at San Raffaele Scientific Institute, Milan. We thank the Centre European of Nano-medicine (CEN, Italy) for the possibility to use Tecnai 20 electron microscope. This work was supported by grants from the Worldwide Cancer Research (16-1245) to S Sigismund; Associazione Italiana per la Ricerca sul Cancro (AIRC IG 18988 and MCO 10.000) and the Italian Ministry of Health to PP Di Fiore; and the Italian Ministry of University and Scientific Research to C Tacchetti and PP Di Fiore (PRIN 2015XS92CC).

\section{Author Contributions}

C Milesi: data curation and investigation.

P Alberici: investigation.

B Pozzi: investigation.

A Oldani: methodology.

GV Beznoussenko: methodology.

A Raimondi: methodology.

BE Soppo: methodology.

S Amodio: methodology.

G Caldieri: data curation and investigation. 
MG Malabarba: data curation and project administration.

G Bertalot: methodology.

S Confalonieri: data curation and methodology.

D Parazzoli: methodology.

AA mironov: methodology.

C Tacchetti: supervision and methodology.

PP Di Fiore: conceptualization, supervision, and funding acquisition.

S Sigismund: conceptualization, data curation, supervision, project administration, and writing-original draft, review, and editing. N Offenhäuser: conceptualization, data curation, supervision, project administration, and writing-original draft, review, and editing.

\section{Conflict of Interest Statement}

The authors declare that they have no conflict of interest.

\section{References}

Benmerah A, Begue B, Dautry-Varsat A, Cerf-Bensussan N (1996) The ear of alpha-adaptin interacts with the $\mathrm{COOH}$-terminal domain of the Eps 15 protein. J Biol Chem 271: 12111-12116. doi:10.1074/ jbc.271.20.12111

Beznoussenko GV, Dolgikh VV, Seliverstova EV, Semenov PB, Tokarev YS, Trucco A, Micaroni M, Di Giandomenico D, Auinger P, Senderskiy IV, et al (2007) Analogs of the Golgi complex in microsporidia: Structure and avesicular mechanisms of function. J Cell Sci 120: 1288-1298. doi: $10.1242 /$ jcs. 03402

Boucrot E, Ferreira AP, Almeida-Souza L, Debard S, Vallis Y, Howard G, Bertot L, Sauvonnet N, McMahon HT (2015) Endophilin marks and controls a clathrin-independent endocytic pathway. Nature 517: 460-465. doi:10.1038/nature14067

Caldieri G, Barbieri E, Nappo G, Raimondi A, Bonora M, Conte A, Verhoef L, Confalonieri S, Malabarba MG, Bianchi F, et al (2017) Reticulon 3-dependent ER-PM contact sites control EGFR nonclathrin endocytosis. Science 356: 617-624. doi:10.1126/science.aah6152

Coda L, Salcini AE, Confalonieri S, Pelicci G, Sorkina T, Sorkin A, Pelicci PG, Di Fiore PP (1998) Eps15R is a tyrosine kinase substrate with characteristics of a docking protein possibly involved in coated pitsmediated internalization. J Biol Chem 273: 3003-3012. doi:10.1074/ jbc.273.5.3003

Confalonieri S, Di Fiore PP (2002) The Eps15 homology (EH) domain. FEBS Lett 513: 24-29. doi:10.1016/s0014-5793(01)03241-0

Confalonieri S, Salcini AE, Puri C, Tacchetti C, Di Fiore PP (2000) Tyrosine phosphorylation of Eps15 is required for ligand-regulated, but not constitutive, endocytosis. J Cell Biol 150: 905-912. doi:10.1083/ jcb.150.4.905

Cousin MA (2009) Activity-dependent bulk synaptic vesicle endocytosis: A fast, high capacity membrane retrieval mechanism. Mol Neurobiol 39: 185-189. doi:10.1007/s12035-009-8062-3

Di Fiore PP, Pelicci PG, Sorkin A (1997) EH: A novel protein-protein interaction domain potentially involved in intracellular sorting. Trends Biochem Sci 22: 411-413. doi:10.1016/s0968-0004(97)01127-4

Elkin SR, Lakoduk AM, Schmid SL (2016) Endocytic pathways and endosomal trafficking: A primer. Wien Med Wochenschr 166: 196-204. doi:10.1007/ s10354-016-0432-7

Fazioli F, Minichiello L, Matoskova B, Wong WT, Di Fiore PP (1993) eps15: A novel tyrosine kinase substrate, exhibits transforming activity. Mol Cell Biol 13: 5814-5828. doi:10.1128/mcb.13.9.5814
Fibach E, Prus E (2005) Differentiation of human erythroid cells in culture. Curr Protoc Immunol Chapter 22:Unit 22F 27. doi:10.1002/0471142735. im22f07s69

Huang F, Khvorova A, Marshall W, Sorkin A (2004) Analysis of clathrinmediated endocytosis of epidermal growth factor receptor by RNA interference. J Biol Chem 279: 16657-16661. doi:10.1074/jbc.c400046200

Iannolo G, Salcini AE, Gaidarov I, Goodman OB Jr., Baulida J, Carpenter G, Pelicci PG, Di Fiore PP, Keen JH (1997) Mapping of the molecular determinants involved in the interaction between eps15 and AP-2. Cancer Res 57: 240-245.

Ishikawa Y, Maeda M, Pasham M, Aguet F, Tacheva-Grigorova SK, Masuda T, Y H, Lee SU, Xu J, Teruya-Feldstein J, et al (2015) Role of the clathrin adaptor PICALM in normal hematopoiesis and polycythemia vera pathophysiology. Haematologica 100: 439-451. doi:10.3324/ haematol.2014.119537

Jones DT, Taylor WR, Thornton JM (1992) The rapid generation of mutation data matrices from protein sequences. Comput Appl Biosci 8: 275-282. doi:10.1093/bioinformatics/8.3.275

Kirchhausen T, Owen D, Harrison SC (2014) Molecular structure, function, and dynamics of clathrin-mediated membrane traffic. Cold Spring Harb Perspect Biol 6: a016725. doi:10.1101/cshperspect.a016725

Kisanuki YY, Hammer RE, Miyazaki J, Williams SC, Richardson JA, Yanagisawa M (2001) Tie2-Cre transgenic mice: A new model for endothelial cell-lineage analysis in vivo. Dev Biol 230: 230-242. doi:10.1006/dbio.2000.0106

Koh TW, Korolchuk VI, Wairkar YP, Jiao W, Evergren E, Pan HL, Zhou Y, Venken KJT, Shupliakov O, Robinson IM, et al (2007) Eps15 and Dap160 control synaptic vesicle membrane retrieval and synapse development. J Cell Biol 178: 309-322. doi:10.1083/jcb.200701030

Kumar S, Stecher G, Tamura K (2016) MEGA7: Molecular evolutionary genetics analysis version 7.0 for bigger datasets. Mol Biol Evol 33: 1870-1874. doi:10.1093/molbev/msw054

Levy JE, Jin O, Fujiwara Y, Kuo F, Andrews NC (1999) Transferrin receptor is necessary for development of erythrocytes and the nervous system. Nat Genet 21: 396-399. doi:10.1038/7727

Lundmark R, Doherty G), Howes MT, Cortese K, Vallis Y, Parton RG, McMahon HT (2008) The GTPase-activating protein GRAF1 regulates the CLIC/GEEC endocytic pathway. Curr Biol 18: 1802-1808. doi:10.1016/j.cub.2008.10.044

Majumdar A, Ramagiri S, Rikhy R (2006) Drosophila homologue of Eps15 is essential for synaptic vesicle recycling. Exp Cell Res 312: 2288-2298. doi:10.1016/j.yexcr.2006.03.030

McMahon HT, Boucrot E (2011) Molecular mechanism and physiological functions of clathrin-mediated endocytosis. Nat Rev Mol Cell Biol 12: 517-533. doi:10.1038/nrm3151

Merrifield CJ, Kaksonen M (2014) Endocytic accessory factors and regulation of clathrin-mediated endocytosis. Cold Spring Harb Perspect Biol 6: a016733. doi:10.1101/cshperspect.a016733

Mettlen M, Stoeber M, Loerke D, Antonescu CN, Danuser G, Schmid SL (2009) Endocytic accessory proteins are functionally distinguished by their differential effects on the maturation of clathrin-coated pits. Mol Biol Cell 20: 3251-3260. doi:10.1091/mbc.e09-03-0256

Muckenthaler MU, Rivella S, Hentze MW, Galy B (2017) A red carpet for iron metabolism. Cell 168: 344-361. doi:10.1016/j.cell.2016.12.034

Nguyen TH, Qiu X, Sun J, Meunier FA (2014) Bulk endocytosis at neuronal synapses. Sci China Life Sci 57: 378-383. doi:10.1007/s11427-014-4636-z

Offenhauser N, Castelletti D, Mapelli L, Soppo BE, Regondi MC, Rossi P, D’Angelo E, Frassoni C, Amadeo A, Tocchetti A, et al (2006) Increased ethanol resistance and consumption in Eps8 knockout mice correlates with altered actin dynamics. Cell 127: 213-226. doi:10.1016/j. cell.2006.09.011

Polishchuk RS, Polishchuk EV, Mironov AA (1999) Coalescence of Golgi fragments in microtubule-deprived living cells. Eur I Cell Biol 78: 170-185. doi:10.1016/s0171-9335(99)80096-x 
Polo S, Confalonieri S, Salcini AE, Di Fiore PP (2003) EH and UIM: Endocytosis and more. SCi STKE 2003: re17. doi:10.1126/stke.2132003re17

Polo S, Sigismund S, Faretta M, Guidi M, Capua MR, Bossi G, Chen H, De Camilli P, Di Fiore PP (2002) A single motif responsible for ubiquitin recognition and monoubiquitination in endocytic proteins. Nature 416: 451-455. doi:10.1038/416451a

Pozzi B, Amodio S, Lucano C, Sciullo A, Ronzoni S, Castelletti D, Adler T, Treise I, Betsholtz IH, Rathkolb B, et al (2012) The endocytic adaptor Eps15 controls marginal zone B cell numbers. PLoS One 7: e50818. doi:10.1371/journal.pone.0050818

Renard HF, Simunovic M, Lemiere J, Boucrot E, Garcia-Castillo MD, Arumugam S, Chambon V, Lamaze C, Wunder C, Kenworthy AK, et al (2015) EndophilinA2 functions in membrane scission in clathrin-independent endocytosis. Nature 517: 493-496. doi:10.1038/nature14064

Robinson MS (2015) Forty years of clathrin-coated vesicles. Traffic 16: 1210-1238. doi:10.1111/tra.12335

Saheki Y, De Camilli P (2012) Synaptic vesicle endocytosis. Cold Spring Harb Perspect Biol 4: a005645. doi:10.1101/cshperspect.a005645

Salcini AE, Chen H, Iannolo G, De Camilli P, Di Fiore PP (1999) Epidermal growth factor pathway substrate 15, Eps15. Int J Biochem Cell Biol 31: 805-809. doi:10.1016/s1357-2725(99)00042-4

Salcini AE, Confalonieri S, Doria M, Santolini E, Tassi E, Minenkova O, Cesareni G, Pelicci PG, Di Fiore PP (1997) Binding specificity and in vivo targets of the EH domain, a novel protein-protein interaction module. Genes Dev 11: 2239-2249. doi:10.1101/gad.11.17.2239

Salcini AE, Hilliard MA, Croce A, Arbucci S, Luzzi P, Tacchetti C, Daniell L, De Camilli P, Pelicci PG, Di Fiore PP, et al (2001) The Eps15 C. elegans homologue EHS-1 is implicated in synaptic vesicle recycling. Nat Cell Biol 3: 755-760. doi:10.1038/35087075

Savio MG, Wollscheid N, Cavallaro E, Algisi V, Di Fiore PP, Sigismund S, Maspero E, Polo S (2016) USP9X controls EGFR fate by deubiquitinating the endocytic adaptor Eps15. Curr Biol 26: 173-183. doi:10.1016/j. cub.2015.11.050

Schumacher C, Knudsen BS, Ohuchi T, Di Fiore PP, Glassman RH, Hanafusa H (1995) The SH3 domain of Crk binds specifically to a conserved proline-rich motif in Eps15 and Eps15R. J Biol Chem 270: 15341-15347. doi:10.1074/jbc.270.25.15341

Sigismund S, Algisi V, Nappo G, Conte A, Pascolutti R, Cuomo A, Bonaldi T, Argenzio E, Verhoef LG, Maspero E, et al (2013) Threshold-controlled ubiquitination of the EGFR directs receptor fate. EMBO J 32: 2140-2157. doi:10.1038/emboj.2013.149

Sigismund S, Confalonieri S, Ciliberto A, Polo S, Scita G, Di Fiore PP (2012) Endocytosis and signaling: Cell logistics shape the eukaryotic cell plan. Physiol Rev 92: 273-366. doi:10.1152/physrev.00005.2011

Sigismund S, Woelk T, Puri C, Maspero E, Tacchetti C, Transidico P, Di Fiore PP, Polo S (2005) Clathrin-independent endocytosis of ubiquitinated cargos. Proc Natl Acad Sci U S A 102: 2760-2765. doi:10.1073/ pnas.0409817102
Sternberg WF, Smith L, Scorr L (2004) Nociception and antinociception during the first week of life in mice: Sex differences and test dependence. J Pain 5: 420-426. doi:10.1016/j.jpain.2004.07.002

Takahashi E, Niimi K, Itakura C (2010) Neonatal motor functions in Cacna1amutant rolling Nagoya mice. Behav Brain Res 207: 273-279. doi:10.1016/ j.bbr.2009.10.017

Tang Y, Harrington A, Yang X, Friesel RE, Liaw L (2010) The contribution of the Tie2+ lineage to primitive and definitive hematopoietic cells. Genesis 48: 563-567. doi:10.1002/dvg.20654

Torrisi MR, Lotti LV, Belleudi F, Gradini R, Salcini AE, Confalonieri S, Pelicci PG, Di Fiore PP (1999) Eps15 is recruited to the plasma membrane upon epidermal growth factor receptor activation and localizes to components of the endocytic pathway during receptor internalization. Mol Biol Cell 10: 417-434. doi:10.1091/mbc.10.2.417

Traub LM (2009) Tickets to ride: Selecting cargo for clathrin-regulated internalization. Nat Rev Mol Cell Bio 10: 583-596. doi:10.1038/nrm2751

Turgeon B, Meloche S (2009) Interpreting neonatal lethal phenotypes in mouse mutants: Insights into gene function and human diseases. Physiol Rev 89: 1-26. doi:10.1152/physrev.00040.2007

van Bergen En Henegouwen PM (2009) Eps15: A multifunctional adaptor protein regulating intracellular trafficking. Cell Commun Signal 7: 24. doi:10.1186/1478-811x-7-24

van Delft S, Govers R, Strous GJ, Verkleij AJ, van Bergen en Henegouwen PM (1997) Epidermal growth factor induces ubiquitination of Eps15. J Biol Chem 272: 14013-14016. doi:10.1074/jbc.272.22.14013

Ventura A, Kirsch DG, McLaughlin ME, Tuveson DA, Grimm J, Lintault L, Newman J, Reczek EE, Weissleder R, Jacks T (2007) Restoration of p53 function leads to tumour regression in vivo. Nature 445: 661-665. doi:10.1038/nature05541

Woelk T, Oldrini B, Maspero E, Confalonieri S, Cavallaro E, Di Fiore PP, Polo S (2006) Molecular mechanisms of coupled monoubiquitination. Nat Cell Biol 8: 1246-1254. doi:10.1038/ncb1484

Wong WT, Schumacher C, Salcini AE, Romano A, Castagnino P, Pelicci PG, Di Fiore PP (1995) A protein-binding domain, EH, identified in the receptor tyrosine kinase substrate Eps15 and conserved in evolution. Proc Natl Acad Sci U S A 92: 9530-9534. doi:10.1073/ pnas.92.21.9530

Zhu BM, McLaughlin SK, Na R, Liu J, Cui Y, Martin C, Kimura A, Robinson GW, Andrews NC, Hennighausen L (2008) Hematopoietic-specific Stat5null mice display microcytic hypochromic anemia associated with reduced transferrin receptor gene expression. Blood 112: 2071-2080. doi:10.1182/blood-2007-12-127480

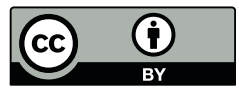

License: This article is available under a Creative Commons License (Attribution 4.0 International, as described at https://creativecommons.org/ licenses/by/4.0/). 